\title{
FORMULASI SEDIAAN MASKER GEL PEEL-OFF DARI EKSTRAK BUAH TOMAT (Solanum Lycopersicum L.) BESERTA UJI AKTIVITAS ANTIOKSIDAN
}

\author{
Wa Ode Sitti Zubaydah ${ }^{*}$, Selly Septi Fandinata ${ }^{2}$ \\ 1 Jurusan Farmasi, Fakultas Farmasi, Universitas Halu Oleo, \\ Jl. HEA Mokodompit, Kampus Hijau Bumi Tridharma Anduonohu Kendari 93232, Indonesia \\ ${ }^{2}$ Farmasi, Akademi Farmasi Surabaya, Jl. Ketintang Madya No. 81 Kota Surabaya 60231, Indonesia \\ *Penulis Korespondensi. Email: woszubaydah@gmail.com
}

\section{ABSTRAK}

Tomat diketaui memilki kandungan antioksidan yang tinggi. Diketahui terdapatat senyawa likopen yang berpotensi menghambat radikal bebas. Dipasaran sediaan yang mengandung antioksidan sudah sangat banyak, salah satunya dalam bentuk sediaan masker gel peel off. Tujuan dari penelitian ini untuk memformulasikan sediaan masker gel peel off dari ekstrak buah tomat, serta untuk mengetahui aktivitas antioksidan dari sediaan masker tersebut dengan menggunakan metode DPPH. Metode penelitian ini diawali dengan mengekstraksi buah tomat secara maserasi menggunakan pelarut alkohol 96\%. Ekstrak kental yang diperoleh kemudian dibuat sediaan masker gel peel off dengan persentase ekstrak sebesar 3\% (F1), 5\% (F2), dan 7\% (F3), dan menggunakan basis PVA 11\% dan viscolam 3\%. Hasil penelitian menunjukkan bahwa sediaan masker gel peel off ekstrak buah tomat yang dihasilkan memenuhi syarat evaluasi fisik dan stabilitas penyimpanan. Hasil uji aktivitas antioksidan menunjukkan nilai $\mathrm{IC}_{50}$ dari ketiga sediaan masker gel peel off ekstrak buah tomat yaitu F1 $189.22 \mu \mathrm{g} / \mathrm{mL}, \mathrm{F} 289.34 \mu \mathrm{g} / \mathrm{mL}$, dan F3 $36.77 \mu \mathrm{g} / \mathrm{mL}$. Berdasarkan uji T-Test diperoleh harga $\mathrm{P}$ value $=0.019(\mathrm{a}=0,05)$, hal tersebut menunjukkan adanya perbedaan hasil uji aktivitas antioksidan ketiga formula pada hari pertama $\left(t_{0}\right)$ dan hari ke $28\left(t_{28}\right)$.

\section{Kata Kunci:}

Masker gel peel off, ekstrak tomat, PVA, viscolam, antioksidan, DPPH.

$\begin{array}{lcc}\text { Diterima: } & \text { Disetujui: } & \text { Online: } \\ \text { 6-07-2020 } & 1-09-2020 & 3-09-2020\end{array}$

\begin{abstract}
Tomatoes are well-known as the source of antioxidants due to the content of lycopene, i.e., a potential free radical inhibitor. Gel peel-off masks are among the chemical products containing antioxidants. The objective of this study is to formulate and examine the antioxidant activity of the gel peel-off mask made of tomato (Solanum Lycopersicum L.) extract using the DPPH method. The first step of the study was extracting tomato fruits by macerating the fruits using alcohol solvents $96 \%$. The obtained thick extract was used as the material of the gel mask; the percentage of the extract comprised 3\% (F1), 5\% (F2), and 7\% (F3), and it used PVA basis $11 \%$ and viscolam 3\%. According to the result, the gel peel-off masks meet the requirements of physical and storage stability evaluation. The result of the antioxidant test reveals that the $\mathrm{IC}_{50}$ value of the three masks is $\mathrm{F} 1189.22 \mu \mathrm{g} / \mathrm{mL}, \mathrm{F} 289.34$ $\mu \mathrm{g} / \mathrm{mL}$, and F3 $36.77 \mu \mathrm{g} / \mathrm{mL}$. Further, the result of T-Test reveals that P-value $=0.019(\mathrm{a}=$ 0.05 ), indicating a difference in the result of the antioxidant test of the three formulae in day one $\left(\mathrm{t}_{0}\right)$ and day $28\left(\mathrm{t}_{28}\right)$.
\end{abstract}


Keywords:

Gel peel-off mask, tomato extract, PVA, viscolam, antioxidants, DPPH.

$\begin{array}{lcc}\text { Received: } & \text { Accepted: } & \text { Online: } \\ \text { 2020-07-6 } & \text { 2020-09-01 } & 2020-09-3\end{array}$

\section{Pendahuluan}

Utamanya bagi seluruh atau sebagian kaum perempuan, kulit merupakan salah satu bagian tubuh yang mendukung penampilan seseorang sehingga perlu menjadi perhatian khusus untuk mendapatkan perlindungan, perawatan, serta patut untuk dijaga kesehatannya. Seiring dengan berjalannya waktu, usia kita juga tentunya semakin bertambah, proses penuaan yang terjadi dikulit bisa disebabkan berbagai faktor, baik faktor dari dalam tubuh maupun luar tubuh manusia. Adapun beberapa hal yang menandakan kulit mengalami penuaan yakni kulit yang mulai terlihat kusam, kulit yang terasa kasar, munculnya bercak-bercak pigmentasi, serta munculnya keriput pada kulit wajah [1].

Salah satu bentuk kosmetik wajah yang banyak beredar dipasaran dan digunakan oleh masyarakat luas yaitu masker. Masker sebagai kosmetik depth cleansing memiliki kinerja secara tepat untuk dapat meregenerasi sel-sel yang tedapat pada kulit. Kegunaan masker salah satunya untuk mengangkat sel-sel tanduk yang telah mengelupas, meremajakan kulit, mengencangkan kulit, mengecilkan pori-pori, memberi kelembaban dan nutrisi pada kulit, dan lain sebagainya [2].

Pada dasarnya dalam tubuh manusia juga menghasilkan senyawa antioksidan yang dikenal degan antioksidan endogen. Namun, karena tingkat paparan dari luar yang begitu tinggi, menyebabkan senyawa ini tidak mampu melindungi tubuh. Oleh sebab itu diperlukan asupan antioksidan dari luar tubuh [3]. Salah satu sumber antioksidan yang alami yaitu terdapat dalam buah tomat (Solanum lycopersicum L.). Dalam buah tomat terkandung senyawa $\beta$ karoten, likopen, polifenol, asam kafeat, asam khlorogenat, rutin dan naringenin. Senyawa-senyawa inilah yang menyebabkan buah tomat dikenal sebagai sumber antioksidan [4].

Berdasarkan penelitian yang dilakukan oleh Agustina Lia, dkk (2017) tentang "Formulasi dan Evaluasi Sabun Mandi Cair dengan Ekstrak Tomat", likopen sebagai kandungan antioksidan yang paling banyak di dalam tomat diformulasikan dalam bentuk sediaan sabun mandi cair yang selanjutnya di uji aktivitas antioksidan dari sediaan sabun mandi cari ektrak buah tomat tersebut. Hasil pengujian menunjukkan, pada uji aktivitas antioksidan sediaan sabun mandi cair ekstrak buah tomat dengan konsentrasi 2,5\% memiliki nilai $\mathrm{IC}_{50} 325.67 \mu \mathrm{g} / \mathrm{mL}$ [5].

Berdasarkan uraian diatas, maka dilakukanlah penelitian lebih lanjut yang mencakup bidang teknologi farmasi serta bahan alam untuk memformulasikan serta pengujian aktivitas antioksidan dari sediaan masker gel peel off ekstrak buah tomat (Solanum lycopersicum L.). Dengan adanya penelitian diharapkan dapat memberikan informasi tentang kandungan senyawa kimia yang terdapat dalam buah tomat sebagai pemanfaatannya dalam kehidupan masyarakat luas. 


\section{Metode}

\subsection{Alat dan Bahan}

Alat-alat yang digunakan pada penelitian ini adalah batang pengaduk, cawan porselen, gelas kimia, gelas ukur, juicer, mortir, neraca digital, oven, penangas air, $\mathrm{pH}$ meter, spektrofotometer UV - Vis, stamper, stopwatch, viscometer Brookfield. Bahanbahan yang digunakan pada penelitian ini adalah Alkohol 70\%, Alkohol 96\%, Aquadestilata, Asam Askorbat, DPPH, Ekstrak buah tomat, Gliserin, Nipagin, Nipasol, PEG 400, Polyvynil Alcohol, TEA, Viscolam.

\subsection{Prosedur Penelitian}

1. Ekstraksi Buah Tomat

Daging buah tomat yang telah dikeringkan dan menajdi serbuk diekstraksi dengan menggunakan alkohol 96\% hingga diperoleh ekstrak cair. Kemudian ekstrak cair yang dihasilkan dipekatkan dengan cara diuapkan hingga menjadi ekstrak kental [6].

\section{Optimasi Basis}

Optimasi basis masker gel peel off dibuat dengan variasi viscolam sebagai gelling agent dan PVA sebagai agen pembentuk film. Adapun formula yang dirancang sebagai berikut :

\begin{tabular}{cccc} 
Tabel 1. Formulasi Sediaan Masker Gel Peel Off Ektrak Buah Tomat \\
\hline Bahan & F1 & Formula $(\%)$ \\
\cline { 2 - 4 } & 7 & 9 & F3 \\
\hline PVA & 1 & 2 & 11 \\
Viscolam & 8 & 8 & 8 \\
Gliserin & 5 & 5 & 5 \\
PEG 400 & 0,18 & 0,18 & 0,18 \\
Nipagin & & & \\
\hline
\end{tabular}

Variasi konsentrasi yang digunakan yaitu F1 PVA 7\% dan viscolam 1\%, F2 PVA 9\% dan viscolam 2\%, F3 PVA 11\% dan viscolam 3\%. Selanjutnya dilakukan evaluasi sediaan secara fisik diantaranya organoleptis, $\mathrm{pH}$, viskositas, dan waktu mengering. Berdasarkan evaluasi basis, diperoleh hasil bahwa basis F3 merupakan basis yang memenuhi semua syarat evaluasi.

\section{Formulasi Sediaan Masker Gel Peel Off Ekstrak Buah Tomat}

Formulasi sediaan dilakukan dengan menggunakan variasi konsentrasi ekstrak yakni F1 3\%, F2 5\%, dan F3 7\%. Adapun bahan lain yang digunakan dalam formulasi ini yaitu meliputi PVA 11\%, viscolam 3\%, nipagin 0,18\%, nipasol 0,02\%, gliserin $8 \%$, PEG $4005 \%$, TEA secukupnya, alcohol $96 \%$ sebanyak $15 \%$, dan aquadest.

\section{Evaluasi Fisik}

1. Uji Organoleptis

Uji organoleptis dilakukan dengan melihat secara langsung perubahan bentuk, bau dan warna dari sediaan masker gel peel off ekstrak buah tomat yang dihasilkan selama waktu penyimpanan.

2. Uji pH

Pengujian $\mathrm{pH}$ sediaan dilakukan dengan menggunakan $\mathrm{pH}$ meter. Adapun rentang $\mathrm{pH}$ sediaan masker gel peel off yang memenuhi syarat evaluasi yaitu sesuai dengan $\mathrm{pH}$ kulit 4,5-7,0. 
3. Uji Viskositas

Pengukuran viskositas sediaan masker gel peel off ekstrak buah tomat dilakukan sebelum dan setelah kondisi penyimpanan. Uji viskositas ini dilakukan dengan menggunakan viscometer Brookfield dengan nomor spindle 7 dan kecepatan sebesar $50 \mathrm{rpm}$.

4. Uji Waktu Mengering

Sebanyak $1 \mathrm{~g}$ masker gel peel off dioleskan pada kulit lengan dengan panjang 7 $\mathrm{cm}$ dan lebar $7 \mathrm{~cm}$. Kemudian dihitung kecepatan mengering masker gel peel off hingga membentuk lapisan film dari masker gel peel off dengan menggunakan stopwatch.

5. Uji Daya Sebar

Pengujian ini dilakukan untuk mengetahui kecepatan dari penyebaran gel sediaan pada kulit saat dioleskan. Adapun persyaratan daya sebar untuk sediaan gel yaitu berkisar pada rentang 5 - $7 \mathrm{~cm}$ [7].

3. Hasil dan Pembahasan

\subsection{Hasil Penelitian}

\section{Ekstraksi Buah Tomat}

Sebanyak 120 gram serbuk buah tomat (Solanum lycopersicum L.) diekstrak menggunakan alkohol 96\% sebanyak $800 \mathrm{~mL}$ dengan menggunakan metode maserasi selama 1 x 24 jam. Didapatkan hasil ekstraksi buah tomat (Solanum lycopersicum L.) berupa ekstrak kental sebesar 16.8 gram.

Tabel 2. Hasil Uji Organoleptis

\begin{tabular}{cccc}
\hline Formula & Warna & $\begin{array}{c}\text { Parameter Uji } \\
\text { Bau }\end{array}$ & Konsistensi \\
\hline F1 & Merah Bata & Khas Buah Tomat & $\begin{array}{c}\text { Setengah padat agak } \\
\text { lunak }\end{array}$ \\
F2 & Merah Bata & Khas Buah Tomat & $\begin{array}{c}\text { Setengah padat } \\
\text { F3 }\end{array}$ \\
\hline
\end{tabular}

Hasil uji organoleptis menunjukkan bahwa formula 1 dan formula 2 memiliki warna sediaan berupa warna merah bata dengan bau yang khas buah tomat serta konsistensi yang setengah padat agak lunak dan setengah padat. Sedangkan untuk uji orgnoleptis formula 3 menunjukkan bahwa sediaan memilki warna merah bata yang kecoklatan, bau yang khas buah tomat, serta konsistensi yang setengah padat .

Tabel 3. Hasil Uji pH

\begin{tabular}{cccc}
\hline $\begin{array}{c}\text { Waktu/T } \\
\text { (Hari) }\end{array}$ & F1 & pH & F3 \\
\hline $\mathbf{0}$ & 7.0 & F2 & 6.8 \\
$\mathbf{7}$ & 7.1 & 6.8 & 6.8 \\
$\mathbf{1 4}$ & 6.7 & 7.0 & 6.5 \\
$\mathbf{2 1}$ & 6.7 & 6.8 & 6.3 \\
$\mathbf{2 8}$ & 6,5 & 6.6 & 6,3 \\
\hline
\end{tabular}

Hasil pengukuran stabilitas $\mathrm{pH}$ yang dilakukan selama 28 hari menunjukkan bahwa ketiga formula menghasilkan $\mathrm{pH}$ cukup stabil. Hal ini telah sesuai dengan $\mathrm{pH}$ kulit manusia yaitu $4,5-7,0[8]$. 
Tabel 4. Hasil Uji Viskositas

\begin{tabular}{cccc}
\hline $\begin{array}{c}\text { Waktu/T } \\
\text { (Hari) }\end{array}$ & F1 & Viskositas (Cps) & F3 \\
\hline $\mathbf{0}$ & 10240 & 13760 & 18000 \\
$\mathbf{7}$ & 8640 & 11360 & 14480 \\
$\mathbf{1 4}$ & 8420 & 10199 & 14130 \\
$\mathbf{2 1}$ & 7940 & 9870 & 12330 \\
$\mathbf{2 8}$ & 7130 & 9210 & 12120 \\
\hline
\end{tabular}

Dari hasil evaluasi viskositas dari ketiga formula sedian masker gel peel off ekstrak buah tomat (Solanum lycopersicum L.) memiliki nilai viskositas sediaan gel yang baik yaitu $2000-50000$ Cps.

Tabel 5. Hasil Uji Daya Sebar

\begin{tabular}{cccc}
\hline $\begin{array}{c}\text { Waktu/T } \\
\text { (Hari) }\end{array}$ & F1 & Daya Sebar $(\mathbf{c m})$ & F2 \\
\hline $\mathbf{0}$ & 6 & 5.6 & 5.4 \\
$\mathbf{7}$ & 5.8 & 5.8 & 5.5 \\
$\mathbf{1 4}$ & 5.8 & 5.7 & 5.4 \\
$\mathbf{2 1}$ & 5.7 & 5.6 & 5.3 \\
$\mathbf{2 8}$ & 5,7 & 5,5 & 5,3 \\
\hline
\end{tabular}

Dari hasil uji waktu mengering sediaan F1, F2, dan F3 memiliki daya sebar yang baik sesuai dengan literature, daya sebar $5-7 \mathrm{~cm}$ menunjukkan konsistensi semisolid yang sangat nyaman dalam penggunaan

Tabel 6. Hasil Uji Waktu Mengering

\begin{tabular}{cccc}
\hline $\begin{array}{c}\text { Waktu/T } \\
\text { (Hari) }\end{array}$ & F1 & Waktu Mengering (menit) \\
F2 & F3 \\
\hline $\mathbf{0}$ & 20,6 & 23,7 & 25,5 \\
$\mathbf{7}$ & 21,2 & 23,2 & 24,5 \\
$\mathbf{1 4}$ & 20,1 & 21,4 & 23,2 \\
$\mathbf{2 1}$ & 19,8 & 21 & 22,6 \\
$\mathbf{2 8}$ & 18,4 & 19,3 & 21,3 \\
\hline
\end{tabular}

Hasil pengujian jmenunjukkan bahwa ketiga formula sediaan masker gel peel off ekstrak buah tomat (Solanum lycopersicum L.) memiliki waktu mengering yang memenuhi syarat yaitu berkisar antara 18 - 21 menit.

\subsection{Pembahasan}

Berbagai macam kandungan senyawa bioaktif yang ditemukan didalam buah tomat (Solanum lycopersicum L.) seperti karotenoid (likopen dan beta karoten), fenol, dan berbagai macam enzim sangat bermanfaat bagi kesehatan. Likopen telah diketahui aktivitas farmakologinya sebagai antioksidan. a-carotene yang merupakan nama lain dari likopen merupakan jenis karotenoid berpigmen merah terang yang biasa ditemukan pada buah tomat dan buah lain yang berwarna merah. Telah banyak penelitian yang mengkonfirmasi bahwa buah tomat memilki potensi antioksidan dan 
anti kanker. Dewasa ini, buah tomat sering diformulasikan sebagai suatu sediaan kosmetik baik berupa krim, sabun mandi cair, dan juga masker.

Dalam penelitian ini buah tomat di bua dalam bentuk sediaan masker gel peel off. Masker gel peel off merupakan masker yang saat digunakan akan mengering kemudian membentuk lapisan film oklusif yang dapat dikelupas. Masker ini mampu meningkatkan efek dari senyawa utama (senyawa aktif) pada bagian epitel disebabkan peranann oklusifitas lapisan polimer. Selain dari pada itu juga masker gel peel off mampu untuk meningkatkan kelembapan kulit [9].

Pada formulasi digunakan beberapa bahan terdiri dari ekstrak buah tomat yang berperan sebagai zat aktif, menggunakan kombinasi humektan yakni gliserin dan PEG 400, PVA sebagai agen pembentuk film, viscolam sebagai gelling agent, kombinasi pengawet yakni nipagin dan nipasol, dan TEA sebagai agen pengalkali. Evaluasi sediaan masker gel peel off ekstrak buah tomat (Solanum lycopersicum L.) terdiri dari organoleptik, uji waktu mengering, uji $\mathrm{pH}$, uji homogenitas, uji daya sebar, dan uji viskositas yang dilakukan evaluasi setiap 7 hari sekali selama 28 hari yang disimpan pada suhu ruang yakni $25^{\circ} \mathrm{C}$.

Berdasarkan hasil evaluasi pengujian organoleptik setelah disimpan selama 28 hari pada suhu kamar $\left(25^{\circ} \mathrm{C}\right)$ sediaan $\mathrm{F} 1, \mathrm{~F} 2$, dan F3 tidak mengalami perubahan baik warna, bau dan konsistensi, dimana sediaan F1 dan F2 memiliki warna merah bata, sedangkan F3 memiliki warna merah bata kecoklatan yang dihasilkan dari penambahan ekstrak buah tomat (Solanum lycopersicum L.) yang digunakan, memiliki bau khas buah tomat yang konsisten dari awal pembuatan bahan sampai waktu penyimpanan serta memiliki konsistensi yang kental. Untuk pengujian homogenitas bertujuan untuk melihat penyebaran zat aktif merata atau tidak. Hasil yang diperoleh yaitu sediaan homogeny dimana tidak adanya agregasi partikel sekunder.

Pada pengujian $\mathrm{pH}$ sediaan, ketiga formula mengalami perubahan $\mathrm{pH}$ setelah dilakukan penyimpanan selama 28 hari pada suhu kamar $\left(25^{\circ} \mathrm{C}\right)$. Sediaan F1, F2, dan F3 pada hari pertama pengujian menunjukkan $\mathrm{pH}$ masing-masing sebesar 7.0, 6,8, dan 6.8. Sedangkan pengujian pada hari ke 28 menunjukkan pH untuk F1 6.5, F2 6.5, dan untuk F3 6.3. Hal ini menunjukkan bahwa semua sediaan sesuai dengan persyaratan $\mathrm{pH}$ kulit wajah yaitu 4,5 - 7.0 [8]. Selain pengujian $\mathrm{pH}$, ketiga sediaan ini juga dilakukan pengujian daya sebar. Hal ini bertujuan untuk mengetahui kemampuan sediaan menyebar pada kulit, dimana yang menjadi syarat masker gel peel off yang baik adalah memiliki kemampuan daya sebar yang merata [10]. Adapun hasil pengujian yang diperoleh pada uji daya sebar sediaan F1, F2, dan F3 mengalami penurunan daya sebar setelah dilakukan penyimpanan selama 28 hari pada suhu kamar $\left(25^{\circ} \mathrm{C}\right)$. Untuk F1 diperoleh daya sebar setelah 28 hari penyimpanan sebesar 5.7 $\mathrm{cm}$, pada F2 daya sebar sebesar $5.6 \mathrm{~cm}$, sedangkan untuk F3 diperoleh setelah 28 hari penyimpanan sebesar $5.4 \mathrm{~cm}$. Semakin tinggi nilai daya sebar masker mengindikasikan konsistensi masker yang lebih lunak. Semakin besar luas 
penyebaran dari sediaan akan lebih mudah digunkana pada saat pengaplikasiaannya pada kulit sehingga absorbsi pada kulit semakin maksimal [11].

Peningkatan konsentrasi PVA pada masing-masing formula menyebabkan penuruan daya sebar, penurunan daya sebar ini terjadi melalui meningkatnya ukuran unit molekul karena telah mengabsorbsi pelarut sehingga cairan tersebut tetahan dan meningkatkan tahanan untuk mengalitr dan menyebar [12]. Perubahan daya sebar yang terjadi pada masing-masing sediaan masih dalam rentang $5-7 \mathrm{~cm}$. Menurut Garg dkk (2002), daya sebar 5-7 cm menunjukkan kualitas konsistensi sediaan yang nyaman dalam penggunaan.

Pada pengujian viskositas, ketiga formula sediaan dilakukan pengujian selama 28 hari pada suhu kamar. Pengukuran viskositas pada hari pertama menunjukkan F1 memiliki viskositas sebesar 10240 Cps, F2 sebesar 13760 Cps, dan F3 memiliki viskositas sebesar 18000 Cps. Peningkatan viskositas gel dipengaruhi oleh peningkatan gelling agent dan agen pembentuk film. Semakin meningkat konsentrasi PVA dapat meningkatkan viskositas sediaan masker gel peel off. Setelah penyimpanan selama 28 hari pada suhu ruang, ketiga formula mengalami penurunan viskositas. Pada F1 sediaan memiliki viskositas 7130 Cps, untuk F2 9210 Cps, sedangkan untuk viskositas sediaan F3 sebesar 12120 Cps. Hal ini sesuai dengan literature yang menunjukkan bahwa viskositas gel yang baik adalah 2000 - 50000 Cps. Viskositas dapat mempengaruhi parameter daya sebar dan pelepasan zat aktif dalam gel, karena gel memiliki viskositas yang optimal akan mampu menahan zat aktif tetap terdispersi dalam basis gel yang mampu meningkatkan konsentrasi gel tersebut [13].

Uji waktu mengering bertujuan untuk mengetahui seberapa lama waktu yang dbutuhkan oleh sediaan hingga mengering sat diaplikasikan pada kulit. Uji waktu mengering ini diharapkan untuk mendapatkan formulasi lapisan film yang baik untuk diaplikasikan, hal ini juga berhubungan dengankenyamanan pengguna saat penggunaanya. Lama pengeringan yang diharapkan dari masker gel peel-off yang dihasilkan adalah antara 15-30 menit [14]. Berdasarkan hasil evaluasi uji waktu mengering F1, F2, dan F3 memiliki waktu mengering yang berbeda-beda. Pada formula 1 memilki waktu mengering selama 22 menit, untuk formula 2 selama 24,6 menit, dan untuk formula 3 selama 26,2 menit. Perbedaan kecepatan pengeringan pada setiap formula dipengaruhi oleh banyaknya konsentrasi air yang terkandung dalam formula sehingga kecepatan pengeringannya akan semakin lama. Selain itu peningkatan konsentrasi PVA juga mempengaruhi lama waktu mengering sediaan. Semakin tinggi konsentrasi PVA, maka semakin lama pula waktu yang dibutuhkan sediaan tesebut untu mengering dan membentuk lapisan film.

Uji aktivitas antioksidan ekstrak buah tomat menggunakan metode DPPH (2,2-difenil1-pikrilhidrazil). Keunggulan dari metode DPPH yakni sederhana, mudah, cepat, akurat dan hanya memerlukan sedikit sampel. Penggunaan metode DPPH pada uji aktivitas antioksidan dikarenakan metode ini mudah digunakan, cepat, teliti dan baik digunakan dalam pelarut organik, khususnya alkohol [15]. Sebelum dilakukan pengukuran absorbansi sampel, dilakukan penentuan panjang gelombang maksimum DPPH dengan menggunakan spektrofotometer UV-Vis, absorbansinya diukur pada 
rentan 400- $800 \mathrm{~nm}$ [16]. Panjang gelombang maksimum DPPH yang didaptkan adalah $515 \mathrm{~nm}$. Pada panjang gelombang tersebut memberikan serapan yang maksimum. Panjang gelombang ini memilki sedikit perbedaan dengan panjang gelombang teoritis, yaitu $517 \mathrm{~nm}$. Akan tetapi batas ini masih diperbelohkan dikarenakan pergeseran yang diperkenankan adalah maksimum sebesar $2 \mathrm{~nm}$ sesuai dengan ketentuan dalam Farmakope Indonesia edisi IV (1995), yaitu.

Uji aktivitas antioksidan dilakukan dalam 28 hari, dimana pengujian dilakukan pada $\mathrm{T}_{0}$ (hari ke-0) dan $\mathrm{T}_{28}$ (hari ke-28). Pada hari ke-0 masing-masing sediaan masker gel peel off ekstrak buah tomat (Solanum lycopersicum L.) diuji aktivitas antioksidan menggunakan metode DPPH. Hasilnya F1 sebesar $189.22 \mu \mathrm{g} / \mathrm{mL}$, F2 sebesar 89.34 $\mu \mathrm{g} / \mathrm{mL}$, dan F3 sebesar $36.77 \mu \mathrm{g} / \mathrm{mL}$. Berdasarkan hasil tersebut F1 merupakan sediaan dengan kekuatan antioksidan yang tergolong lemah karena memiliki nilai IC50 150-200 $\mu \mathrm{g} / \mathrm{mL}$, untuk sediaan F2 tergolong sebagai antioksidan kuat karena memiliki nilai IC50 50-100 $\mu \mathrm{g} / \mathrm{mL}$ dan F3 merupakan sediaan dengan antioksidan yang tergolong sangat kuat karena memiliki IC50 50-100 $\mu \mathrm{g} / \mathrm{mL}$.

Setelah 28 hari dilakukan uji pada hari ke-28 dengan suhu penyimpanan $25^{\circ} \mathrm{C}$ (suhu kamar) dilakukan uji aktivitas antioksidan kembali terhadap masing-masing sediaan, hasilnya terjadi penurunan pada masing-masing sediaan. F1 sebesar $259.79 \mu \mathrm{g} / \mathrm{mL}, \mathrm{F} 2$ sebesar $132.29 \mu \mathrm{g} / \mathrm{mL}$, dan F3 sebesar $98.79 \mu \mathrm{g} / \mathrm{mL}$. Berdasarkan hasil yang didapat, F1 mengalami penurunan kekuatan antioksidan yang tergolong kurang aktif. Pada F2 juga mengalami penurunan kekuatan antioksidan yang tergolong sedang dan pada F3 mengalami penurunan aktivitas antioksidan yang tergolong kuat.

Berdasarkan perubahan nilai aktivitas antioksidan dari masing-masing formula dapat disimpulkan bahwa sediaan bentuk masker gel peel off memiliki kemampuan antioksidan yang lebih tinggi dengan komposisi ekstrak 7\% (F3). Sediaan F3 pada hari ke-0 dan setelah 28 hari masih memiliki aktivitas dengan kekuatan yang lebih tinggi dibanding yang lainnya. Aktivitas antioksidan ketiga formula dari hari pertama $\left(\mathrm{t}_{0}\right)$ dan hari ke $28\left(\mathrm{t}_{28}\right)$ di uji menggunakan paired T-Test, untuk melihat perbedaan bermakna nilai aktivitas antioksidan ketiga sediaan. Diperoleh harga $P$ value $=0.019$ ( $\alpha$ $=0,05$ ), hal tersebut menunjukkan adanya perbedaan hasil uji aktivitas antioksidan ketiga formula pada hari pertama $\left(t_{0}\right)$ dan hari ke $28\left(t_{28}\right)$.

\section{Kesimpulan}

Ekstrak buah tomat (Solanum lycopersicum L.) dapat diformulasikan dalam bentuk sediaan masker gel peel off, dimana sediaan F1 (3\%), F2 (5\%) dan F3 (7\%) telah memenuhi uji stabilitas fisik yang meliputi uji organoleptik, uji $\mathrm{pH}$, uji daya sebar, uji waktu mengering, uji viskositas selama penyimpanan 28 hari. Dari ketiga formula masker gel peel off ekstrak buah tomat (Solanum lycopersicum L.), hasil aktivitas antioksidan menunjukkan nilai $\mathrm{IC}_{50}$ dari ketiga sediaan masker gel peel off ekstrak buah tomat yaitu F1 $189.22 \mu \mathrm{g} / \mathrm{mL}, \mathrm{F} 289.34 \mu \mathrm{g} / \mathrm{mL}$, dan F3 $36.77 \mu \mathrm{g} / \mathrm{mL}$. 
Referensi

[1] Maysuhara, S. 2009. Rahasia Cantik, Sehat, dan Awet Muda, Edisi 1. Yogyakarta: Pustaka Panasea.

[2] Septiari, dan Suhartiningsih. 2014. Pengaruh Proporsi Puree Stroberi (Fragaria vesca L.) dan Tapioka Terhadap Kualitas Masker Wajah Tradisional. Surabaya : Universitas Negeri Surabaya.

[3] Umayah. E., dan Amrun, M. 2007. Uji Aktifitas Antioksidan Ekstrak Buah Naga (Hylocereus undatus (Haw.) Britt \& Rose). Jurnal Ilmu Dasar.

[4] Tyssandier,V., et all. 2004. Effect of Tomato Product Consumption On The Plasma Status of Antioxidant Microconstituents and On The Plasma Total Antioxidant Capacity In Healthy Subjects. United Stated : US National Library of Medicine National Institutes of Health.

[5] Agustina, L., Yulianti, M., Shoviantari, F., Sabban, I. F. 2017. Formulasi dan Evaluasi Sabun Mandi Cair dengan Ekstrak Tomat (Solanum lycopersicum L.) Sebagai Antioksidan. Jurnal Wiyata Vol 4(2)

[6] Fery Indradewi Armadany, Hasnawati, Morita Sirait. 2013. Formulasi Sediaan Masker Gel Peel-off Antioksidan dari Ekstrak Sari Tomat (Solanum lycopersicum L. var. cucurbita). Kendari : Fakultas Farmasi Universitas Halu Oleo.

[7] Garg, A., Deepika, S., and A. K. Sigla. 2002. Spreading of Semisolid Formulation. USA : Pharmaceutical Technology.

[8] Tranggono, R.. I., Latifah, F. 2007. Buku Pegangan Ilmu Pengetahuam Kosmetik. Jakarta : PT. Gramedia Pustaka Utama.

[9] Vieira, Rafael Pinto, el al. 2009. Physical and Physicochemical Stabilitty Evaluation of Cosmetic Formulations Containing Soybean Extract Fermented by Bifidobacterium Animals. Brazilian Journal of Pharmaceutical Science Vol. 45 No. 3.

[10] Naibaho, D. H., Yamkan, V. Y., Weni, W. 2013. Pengaruh Basis Salep Terhadap Formulasi Sediaan Salep Ekstrak Daun Kemangi pada Kulit Punggung Kelinci yang dibuat Infeksi S. aureus. Sulawesi Utara: Journal Ilmiah Farmasi Unsrat

[11] Andini, T., Yusriadi., Yullet. 2017. Optimasi Pembentuk Film Polivinil Alkohol dan Humektan Propilen Glikol pada Formula Masker Gel Peel Off Sari Buah Labu Kuning Sebagai Antioksidan. Jurnal Farmasi Galenika Volume 3(2)

[12] Martin, A., Swarbick, J., dan A. Cammarata. 1993. Farmasi Fisik Edisi III. Jakarta: UI Press

[13] Madan, J., dan Singh, R. 2010. Formulation and Evaluation of Aloevera Topical Gels. International Journal Pharmacy Science Vol 2 (2)

[14] Nurrochmah, B. 2012. Optimasi Film Agent Polyvinil Alcohol dan Humektan Gliserin dalam Formula Gel Masker Peel Off Anti Acne dari Ekstrak Daun Kemangi. Yogyakarta: Universitas Sanata Dharma 
[15] Pourmorad, F., Hosseinimehr, S. J., Shahabimajd, N. 2006. Antioxidant Activity, Phenol, and Flavonoid Content of Some Selected Iranian Medical Plants. African Journal of Biotechnology

[16] Musfiroh Dam Syarief. 2009. Uji Aktivitas Peredaman Radikal Bebas Nano Partikel Drugs dengan Berbagai Konsentrasi Sebagai Material Antiaging dalam Kosmetik. UNESA Journal Of Chemistry 